\title{
The doctor's advice and sleepless nights: what can you find in 5 minutes?
}

They have no physicians, but when a man is ill they lay him in the public square, and the passersby come up to him, and if they have ever had his disease themselves or have known anyone who has suffered from it, they give him advice, recommending to do whatever they found good in their own cases, or in the case known to them. And no-one is allowed to pass the sick man in silence without asking him what his ailment is.

Herodotus 484-424 BC (Greek Historian)

Key to symbols

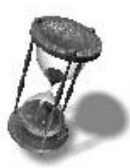

Search time to retrieve article-maximum 5 minutes

Number of clicks to obtain the relevant article

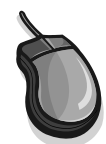

THE PROBLEM

While teaching medical undergraduates EBM one day, we digressed to discuss the advice they give and how this is perceived the nearer they are to becoming a doctor. Family members and friends were already seeking their counsel, and this led me to question my own advice. Next day in my general practice clinic, I start to offer advice to the mother of a 16 month old child bent on wrecking her mother's marriage by refusing to sleep at night. It appeared the child was taking too much milk ( $7-8$ bottles a day including 2 at night), was difficult to settle, and then woke within 2 hours of going to bed. Both parents worked shifts and were inconsistent in their approach. I told the mother that I would like to see the whole family together, and, meanwhile, the plan was to decrease the amount of milk feeds. The health visitor was on holiday so I left myself a note to search for an answer.

\section{SEARCHING AND APPRAISAL}

My usual approach to searching is this: firstly, look in the Cochrane Library for systematic reviews and then for trials in the controlled trials register, and, secondly, search Medline via PubMed Clinical Queries. However, a different tack was needed for this problem. I needed some helpful tips as much as evidence, so my first port of call was my wife ("mum knows best"). She recommended the National Childbirth
Trust's book of sleep. We also talked about bedtime routines, winding down time, and setting a clear strategy for when a child wakes in the night. A useful tip was to use a continental style sleeping bag so the child doesn't wake when he/she kicks off the bed clothes.

\section{My wife}

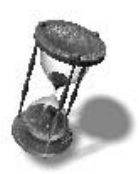

5 minutes.

My first search was the National Electronic Library for Health (http://www.nelh.nhs.uk/), which gives access to evidence and patient information. My first search term was sleep yielding 108 hits, of which 2 were patient information; unfortunately, these related to sleep apnoea and snoring. Next I combined the terms sleep AND child and obtained 1 hit on nocturnal enuresis. Finally, I used the asterisk for truncation (sleep AND child*), which yielded 10 hits, of which 7 were evidence sources.

\section{National electronic Library for Health}
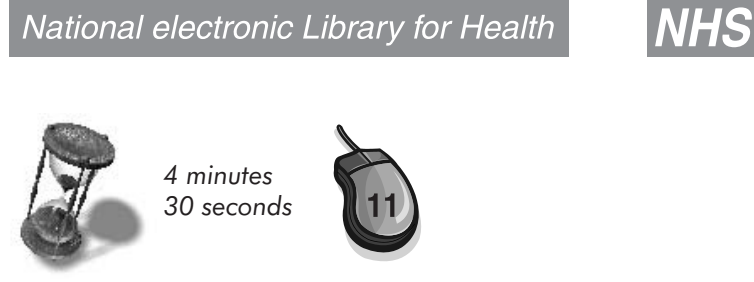

The first of these was a systematic "Review of treatments for settling problems and night waking in young children" published in the BMJ, ${ }^{1}$ with the full text article downloadable via the BMJ website (http://www.bmj.com). Subjects included in this review were $\leqslant 5$ years of age, and studies needed to use a placebo, waiting list, or another intervention as a comparison. Nine trials met these inclusion criteria: 4 drug trials, 4 trials on behavioural treatments, and 1 trial on a general non-directive educational approach. Two drug trials of trimeprazine (compared with placebo) showed a statistically significant positive effect in the short term. Up to one third of the children on drug treatment did not improve with the intervention, and there was no convincing evidence of long term benefit.

Behavioural treatments included positive routines, graduated extinction, scheduled waking, extinction or systematic ignoring, modified extinction, an educational booklet, or a sleep programme (table). In both the short and long terms, scheduled waking and extinction were more effective in 
reducing night waking than was control treatment (a sleep diary). Positive routines and graduated extinction were more effective in reducing settling problems than was a waiting list. A non-directive educational booklet showed no benefit over a control procedure. The benefits of a modified extinction procedure and of a booklet giving specific advice were unclear because no control group comparisons were done.

I could have found the same review more quickly using EBM online (http://evidence-basedmedicine.com) with the search term sleep. This yielded 5 hits and a summary of the above article. $^{2}$ The commentary section pointed to some additional lessons: drugs are of little help in the long term, and studies using psychotropic drugs are unlikely to be representative of the normal population, as many parents would not let their children take part in such a trial.

\section{EBM Online \\ Evidence-Based Medicine}

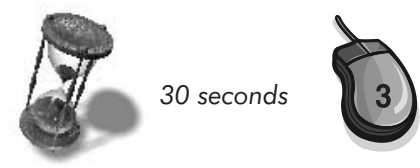

Most of my patients and many practising physicians use Google. Using SLEEP YOUNG CHILDREN DISORDERS ADVICE obtained 152000 hits. The first of these was the About site on sleep disorder and sleep advice (http://pediatrics.about.com/ od/sleep). I tried the Children's Sleep Quiz, and got 3 out of 4 questions correct and was told I was "not bad, but I should likely read more about children's sleep problems to make sure my kids are getting a good nights sleep!" Sections included the Top Ten Sleeping Books for children and Ask The Expert, but the number of pop up adverts led to my exit as my 5 minute window was up. There was insufficient time to see who was offering the advice or how it was selected. Internet search engines can be useful for answering background questions, but foreground questions (specific questions on management of a problem) will often result in a time consuming search. These sites often give the impression that the information is based on sound research, but it can be difficult to tell whether this is so.
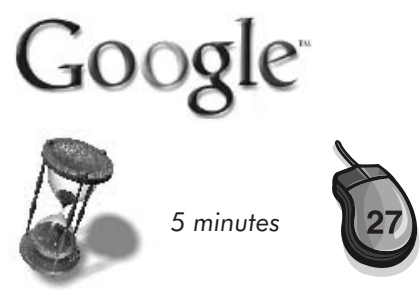

\section{APPLICATION}

The next consultation, the parents said they had dropped the night time feeds but were concerned waking may be a result of their son throwing off the bed clothes at night. Being a general practitioner is about listening and allowing people to formulate their own ideas and giving them small chunks of information. We discussed the continental sleeping bags for children and the consistency of the approach: wind down time, positive routines, and gradual wind down times. I arranged for follow up with the health visitor who would see them if there were any further problems. I later heard things were improving, with the child able to sleep through the night, but getting off to sleep was still a problem.

\section{REFLECTIONS ON THE PROCESS}

Advice denotes an opinion as to a decision or course of action. Formulating these opinions relies on a number of elements: our own experiences, experiences of others, expert opinion, the evidence, and the mechanism of the action (does it make sense?). These can be thought of as the legs of a table.

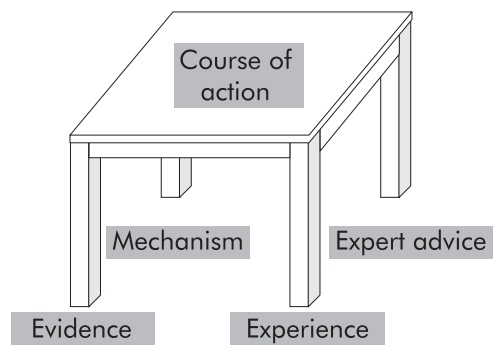

Patients will have their own ideas and interpretations. Lack of access to additional elements may lead to an inability to decide: if you live far from family you may not have anyone to turn to. "Expert advice" does not necessarily come from a health professional but from any source you trust-an individual or group whose opinion you believe.

The problem is not life threatening, but it is common and can be disabling to parents. I used various sources to build my plan of action. More usually we rely on a single or no source! An indepth exploration of how primary care clinicians make decisions noted that they rarely accessed and used explicit research directly. ${ }^{3}$ They were informed by their own and their colleagues' experiences; their interactions with each other and with opinion leaders, patients, and pharmaceutical representatives; and other sources of largely tacit knowledge. With effective searching strategies, it was relatively simple and easy to find a relevant study through several sources. As part of Step 5, I recommend you sometimes try out a few different ones on the same question.

I owe my success to having listened respectfully to the very best advice, and then going away and doing the exact opposite.

$$
\text { G K Chesterton (1874-1936) }
$$

Acknowledgements:

Many thanks to my partner Mary Coombs and the staff of Millstream Surgery Benson.

CARL HENEGHAN, BM, BCH, BA(HONS) OXON Dept of Primary Health Care, University of Oxford Mill Stream Surgery, Benson

1 Ramchandani P, Wiggs L, Webb V. A systematic review of treatments for settling problems and night waking in young children. $B M J$ 2000;320:209-13.

2 Review: long term effectiveness of non-drug treatments for sleep problems in young children is more evident. Klaus Minde (commentator). Evidence-Based Medicine 2000;5: 148

3 Gabbay J, le May A. Evidence based guidelines or collectively constructed "mindlines?" Ethnographic study of knowledge management in primary care. BMJ 2004;329:1013. 
Description of behavioural treatments ${ }^{2}$

\begin{tabular}{|c|c|}
\hline Positive routines & 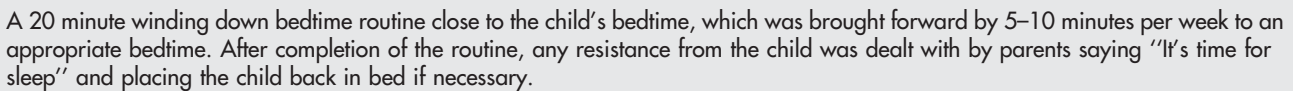 \\
\hline Graduated extinctions & $\begin{array}{l}\text { Parents ignored bedtime tantrums for preset time intervals, the duration of which increased each week. At the end of the interval, } \\
\text { parents entered the room, put the child back in bed if necessary, and told them it was "time for sleep" before leaving the room again } \\
\text { after a maximum of } 15 \text { seconds. }\end{array}$ \\
\hline Scheduled waking & $\begin{array}{l}\text { arents were instructed to wake their child 15-60 minutes before the child usually woke spontaneously and to resettle them to sleep in } \\
\text { leir usual manner. Number and timing of scheduled wakes were modified on a semi-weekly basis, depending on the child's sleep } \\
\text { atterns during the previous few nights. }\end{array}$ \\
\hline $\begin{array}{l}\text { Extinction or systematic } \\
\text { ignoring }\end{array}$ & $\begin{array}{l}\text { Parents went to their children when they were first heard to cry, checked that they were not ill, and changed nappies in the cot if } \\
\text { necessary but did not pick the children up or soothe, feed, or interact with them in any way. Once reassured that the child was not ill, } \\
\text { parents left the room and did not return for the duration of that crying episode. Further crying episodes each night were dealt with in } \\
\text { the same way. }\end{array}$ \\
\hline Modified extinction & $\begin{array}{l}\text { This involved parents ignoring their child for } 20 \text { minutes, and then checking that the child was not ill, but they did not pick up, soothe, } \\
\text { interact with, or feed the child. Having reassured themselves, parents left the room and returned only after the child had displayed a } \\
\text { settling problem or night waking for a further } 20 \text { minutes. This } 20 \text { minute checking interval was maintained throughout treatment. } \\
\text { "Support visits," used in conjunction with modified extinction, consisted of a visit from the therapist every } 2 \text { or } 3 \text { days during the first } 3 \\
\text { weeks of treatment. }\end{array}$ \\
\hline Educational booklet & $\begin{array}{l}\text { General information about children's sleep, described the advantages and disadvantages of the range of treatments for children's } \\
\text { sleep problems, and emphasised that there was no } 1 \text { solution. Supportive visits, used in conjunction with the booklet, consisted of non- } \\
\text { directive discussion with an untrained counsellor about the children's sleep. }\end{array}$ \\
\hline Sleep programme & $\begin{array}{l}\text { Individually tailored behavioural programmes (using a variety of techniques which were also described in the accompanying booklet) } \\
\text { with daily support telephone calls at first, decreasing in frequency over time, accompanied by a behavioural advice booklet. }\end{array}$ \\
\hline
\end{tabular}

\section{Correction}

$\mathrm{T}$

he editors regret the omission of Dr Stuart Carney and Ms Helen Doll as authors of a recent EBM notebook. ${ }^{1}$ We apologise to Dr Carney and Ms Doll. The authorship information should be as follows:

STUART CARNEY, MB, ChB, MPH, MRCPsych

Department of Psychiatry, University of Oxford

Oxford, UK
HELEN DOLL, BSc, Dip App Stats, MSc Department of Public Health, University of Oxford Oxford, UK

1 Carney S, Doll H. Measurement scales and their summary statistics. EvidenceBased Medicine 2004;9:164-6.

\section{Journals reviewed for this issue*}

Acta Obstet Gynecol Scand

Age Ageing

Am J Cardiol

Am J Med

Am J Obstet Gynecol

Am J Psychiatry

Am J Public Health

Am J Respir Crit Care Med

Ann Emerg Med

Ann Intern Med

Ann Surg

Arch Dis Child

Arch Gen Psychiatry

Arch Intern Med

Arch Neurol

Arch Pediatr Adolesc Med
Arch Surg
Arthritis Rheum
BJOG
BMJ
Br J Gen Pract
Br J Psychiatry
Br J Surg
CMAJ
Chest
Circulation
Cochrane Library
Crit Care Med
Diabetes Care
Gastroenterology

Gut

Heart

Hypertension

JAMA

J Am Coll Cardiol

J Am Coll Surg

$\mathrm{J}$ Am Geriatr Soc

$\mathrm{J}$ Clin Epidemiol

J Fam Pract

J Gen Intern Med

$J$ Infect Dis

J Intern Med

J Neurol Neurosurg Psychiatry

$\mathrm{J}$ Pediatr
J Vasc Surg

Lancet

Med Care

Med J Aust

$\mathrm{N}$ Engl J Med

Neurology

Obstet Gynecol

Pain

Pediatrics

Rheumatology

Spine

Stroke

Surgery

Thorax

*Approximately 60 additional journals are reviewed. This list is available on request. 